\title{
UM LEGADO DE JOHN DEWEY PARA A ADMINISTRAÇÃO ESCOLAR: UMA LEITURA DA OBRA VIDA E EDUCAÇÃO
}

\author{
UN LEGADO DE JOHN DEWEY PARA LA ADMINISTRACIÓN ESCOLAR: UNA \\ LECTURA DE LA OBRA VIDA Y EDUCACIÓN
}

\section{A LEGACY OF JOHN DEWEY FOR SCHOOL ADMINISTRATION: A READING OF THE WORK LIFE AND EDUCATION}

\author{
Abelardo Bento ARAÚJO ${ }^{1}$
}

RESUMO: Este artigo tem por objetivo discutir contribuições da obra "Vida e educação", de John Dewey, para a administração escolar. Para isso, analisam-se os fins da escola propostos por Dewey na referida obra, mediante um conceito de administração escolar como mediação para a realização de fins determinados. Verifica-se que Dewey contribui para a administração escolar, na medida em que propõe a democracia como princípio que deve orientar a educação - entendida em seus aspectos administrativos e pedagógicos, de forma indissociada.

PALAVRAS-CHAVE: Dewey. Democracia. Administração escolar.

RESUMEN: Este artículo tiene por objetivo discutir contribuciones de la obra "Vida y educación", de John Dewey, para la administración escolar. Para ello, se analizan los fines de la escuela propuestos por Dewey en la referida obra, mediante un concepto de administración escolar como mediación para la realización de fines determinados. Se observa que Dewey contribuye a la administración escolar, en la medida en que propone la democracia como principio que debe orientar la educación - entendida en sus aspectos administrativos y pedagógicos, de forma indisociada.

PALABRAS CLAVE: Dewey. Democracia. Administración escolar.

ABSTRACT: This article aims to discuss contributions of John Dewey's "Life and education" to school administration. For this, the purpose of the school proposed by Dewey in the referred work is analyzed, through a concept of school administration as mediation for the accomplishment of determined ends. It appears that Dewey contributes to the school administration, in that it proposes democracy as a principle that must guide education understood in its administrative and pedagogical aspects, in an undissociated way.

KEYWORDS: Dewey. Democracy. School Administration.

${ }^{1}$ Centro Federal de Educação Tecnológica de Minas Gerais (CFETMG), Belo Horizonte - MG - Brasil. Doutor em Educação pela Universidade de São Paulo (USP). Pedagogo do Centro Federal de Educação Tecnológica de Minas Gerais. ORCID: <https://orcid.org/0000-0002-2441-0384>. E-mail: abelardo.bento@gmail.com

RPGE- Revista on line de Política e Gestão Educacional, Araraquara, v. 23, n. 2, p. 356-369, maio/ago., 2019. E-ISSN:1519-9029. 


\section{Introdução}

Ao discutir a natureza e a função da administração na educação, Anísio Teixeira (1968) diz que a administração escolar requer, sobretudo, o conhecimento do fenômeno educativo, porque compreende que a administração deve estar subordinada à natureza e aos fins da atividade que tem por objeto. Tendo presente a importância da obra de John Dewey para o conhecimento do fenômeno educativo, este artigo tem como objetivo discutir implicações das concepções contidas em "Vida e educação" para a Administração Escolar. Leva-se em conta o tempo em que Dewey viveu e produziu a obra, visualizando, porém, um legado filosófico que transcende o tempo.

Para atender ao objetivo proposto, analisa-se o clássico "Vida e educação", escrito por Dewey no início do século XX, buscando compreender seus fundamentos principais. Para pensar a contribuição da obra para a reflexão na área da Administração Escolar atual, recorrese ao conceito de Administração Escolar nos textos de Vitor Henrique Paro (2001; 2010a; 2010b; 2012), que, embora com bases teóricas diferentes das de Dewey, propõe um conceito de administração como mediação para a consecução de fins determinados.

O artigo está estruturado em seis partes, incluindo esta introdução. Na segunda parte, a seguir, discute-se o interesse e a experiência democrática a partir da obra "Vida e educação", no contexto da Escola Nova. Na terceira parte, aborda-se o significado e a importância da direção e do controle na aprendizagem da criança. Na quarta parte, trata-se da lógica de organização das aprendizagens contida na obra. Na quinta parte, discute-se o caráter mediador da Administração Escolar. Por fim, tecem-se algumas considerações acerca das contribuições de "Vida e educação" para o campo da Administração Escolar.

\section{Escola Nova, interesse e experiência democrática}

John Dewey (1859-1952) é um dos precursores da Escola Nova, proposta que, embora congregue diversas vozes e concepções, orientou-se pela crítica à Escola Tradicional, desde os fins do século XIX, tendo ganhado expressividade no início do século XX. A Escola Nova questionou as imposições curriculares e didáticas da Escola Tradicional, que se faziam em detrimento do desenvolvimento da individualidade dos sujeitos. Propôs a pesquisa e a atividade livre dos educandos, deslocando, portanto, o centro dos processos educativos da figura do professor para os alunos. Verificam-se descontinuidades radicais da Escola Nova em relação à Pedagogia Tradicional que se vinha consolidando a partir do surgimento da educação em massa, 
posto que a Escola Nova questionava as principais concepções que orientavam as práticas da educação nos moldes tradicionais. No contexto da modernidade, a Escola Nova advogava uma educação fundamentada em princípios científicos. Por exemplo, posicionava-se contrariamente aos castigos escolares, as punições, por entender que essas práticas não se sustentavam em princípios científicos da educação.

Nesse recorte ideológico situa-se John Dewey, para quem “o objetivo da educação é habilitar os indivíduos a continuar sua educação - ou que o objetivo ou recompensa da aprendizagem é a capacidade de desenvolvimento constante" (WESTBROOK, 2010, p. 73). Porém, esse objetivo só poderia ser alcançado em condições democráticas. Isto é, quando as relações entre as pessoas fossem mútuas e houvesse condições adequadas para a discussão e reconstrução de costumes e instituições sociais orientadas pela distribuição equitativa de interesses

De acordo com Lourenço Filho (1959), Dewey compreende a escola como parte inerente da totalidade social. Trata-se de uma escola como uma pequena comunidade, em que todos os processos de vida não devem ser diferentes dos que estão ao seu redor, mas não pode ser uma representação artificial em miniatura da sociedade, pois, para Dewey, a educação não é uma preparação a priori para a vida; é parte da própria vida. Então, é necessário viver na escola aquilo que é desejável viver na sociedade. Essa defesa que Dewey faz da necessidade da experiência democrática na escola tem a ver com a sociedade democrática que vislumbra.

A teoria geral da educação que vimos expondo [a de Dewey] deixa subentendido que a contínua reconstrução da experiência, individual ou social, somente pode ser aceita e conscientemente buscada por sociedades progressivas ou democráticas, que visem não apenas a simples preservação dos costumes estabelecidos, mas a sua constante renovação e revisão (TEIXEIRA, 1959, p. 31).

O contexto da produção da obra de Dewey é a América do Norte num período de busca, por meio também da escola, da conformação dos cidadãos em geral e especialmente dos imigrantes, ao modo de vida americano. Naquele contexto, surgia, por um lado, o questionamento da relação entre o currículo e a vida das crianças - no qual Dewey se insere e, por outro, o da utilidade da educação para o que essas crianças e jovens faziam - o tecnicismo. E o que estes faziam ou iriam fazer tinha ligação também com o trabalho industrial. No entanto, para além do contexto de produção de sua obra, Dewey defende o desenvolvimento da personalidade, porque preocupado com o a especificidade do fenômeno educativo: “o ideal não é a acumulação de conhecimentos, mas o desenvolvimento de capacidades. Possuir todo um 
conhecimento do mundo e perder a sua própria individualidade é destino tão horrível em educação como em religião" (DEWEY, 1959, p. 55-56).

Entendendo que Dewey pensava em uma educação para uma sociedade democrática e que visava ao desenvolvimento da personalidade - porque não dizer à afirmação do indivíduo como sujeito -, pode-se coadunar a perspectiva de educação de Dewey como prática democrática no sentido que Paro (2010a, p. 27) aplica à democracia: "convivência pacífica e livre entre pessoas e grupos que se afirmam como sujeitos" (grifo no original).

Anísio Teixeira define a educação em Dewey, como "processo de reconstrução e reorganização da experiência, pelo qual lhe percebemos mais agudamente o sentido, e com isso nos habilitamos a melhor dirigir o curso de nossas experiências futuras" (TEIXEIRA, 1959, p. 8). Tal como Lourenço Filho, Teixeira (1959) reconhece a educação deweyana como "fenômeno direto da vida, tão inelutável quanto a própria vida". E completa: "a contínua reorganização e reconstrução da experiência pela reflexão, constitui o característico mais particular da vida humana, desde que emergiu do nível puramente animal" (TEIXEIRA, 1959, p. 8). No contexto da filosofia pragmatista americana, Dewey postula a melhoria da qualidade da experiência por meio da inteligência ${ }^{2}$. Defende também que os conhecimentos não se tornem fins em si mesmos, mas que se integrem à vida do cidadão, tornando-se úteis nela. Por essa razão, teme que a escola ofereça um ensino que nada tenha a ver com a vida.

Para Dewey, a educação é fenômeno que se realiza particular e internamente. Teixeira (1959) esclarece, inclusive usando verbos reflexivos na primeira pessoa:

Eu me educo através de minhas experiências vividas inteligentemente. Existe, sem dúvida, certo decurso de tempo em cada experiência, mas assim as primeiras fases como as últimas do processo educativo, têm igual importância, e todas colaboram para que eu me instrua e me eduque - instrução e educação que não são os resultados externos da experiência, mas a própria experiência reconstruída e reorganizada mentalmente no curso de sua elaboração (TEIXEIRA, 1959, p. 09).

O estudante se educa, mas isso não dispensa a ação do professor como quem cria e organiza as condições para que esse estudante experimente e aprenda. Aliás, para Dewey, a educação é mesmo uma constante reconstrução da experiência de forma a conferir cada vez mais sentido, processo por meio do qual as gerações mais jovens se habilitam a responder aos desafios que se lhes apresentam na vida e na sociedade.

2 Importante ressaltar que o pragmatismo americano tem suas raízes ligadas ao empirismo inglês, embora Dewey tenha criticado veementemente as aspirações baconianas, especialmente em relação ao conceito de experiência. Para ele, Bacon insistia no método científico e ignorava o mundo da vida (OZMAN; CRAVER, 2004). 
Nesse sentido, convém esclarecer o que é a experiência para Dewey: "Esse agir sobre outro corpo e sofrer de outro corpo uma reação é, em seus próprios termos, o que chamamos de experiência” (TEIXEIRA, 1959, p. 1). Dewey insiste que a verbalização se subordina aos processos de experiência, que não se educa diretamente pela palavra. Mesmo reconhecendo que a palavra possa ampliar a experiência, entende a educação verbal como subordinada à compreensão e reconstrução imaginativa da experiência.

\title{
A direção e o controle na ação pedagógica da escola do interesse
}

Ao contrário do que as críticas recebidas pela Escola Nova postularam, a direção e o controle fazem parte do conjunto de concepções do ensino renovado. Isso fica claro quando Dewey alerta para os perigos tanto da nova quanto daquela que chama de velha educação.

\begin{abstract}
A "velha educação" tinha a tendência para ignorar a qualidade dinâmica, a força intrínseca de desenvolvimento da experiência infantil; e daí pressupor que direção e controle eram inteiramente arbitrários, consistindo em pôr a criança em determinado caminho e compeli-la a segui-lo. A "educação nova" está em perigo de tomar a ideia do desenvolvimento de um modo muito vazio e formal. Espera-se que a criança desenvolva este ou aquele fato ou ideia, de seu próprio espírito. Queremos que ela pense sobre as coisas ou que ela aja, sem supri-la das condições indispensáveis para despertar e guiar o pensamento (DEWEY, 1959, p. 66, grifos no original).
\end{abstract}

Não é demais lembrar, depois dessa citação, que o ensino funcional é meio e nunca fim para a educação renovada. Por essa citação ainda se percebe que centrar a educação no interesse não é dispensar a ação do adulto na educação da criança. O professor continua tendo um papel importante. Acontece que a centralidade não pertence mais a apenas um desses sujeitos.

Entendendo que educação é processo interno e individual, Dewey postula que o meio direto de direção da educação - isto é, o meio pelo qual se deve realizar a ação do educador não é senão “o de preparar o ambiente em que a criança age, pensa e sente” (TEIXEIRA, 1959, p. 19). As ações interventivas dos educadores ocorrerão, então, no âmbito da possibilidade da ação sobre o meio, na sua modificação, alteração, organização intencional para o efeito educativo.

As escolas, por sua vez, são também meios organizados intencionalmente para o fim expresso de influir moral e mentalmente sobre os seus membros. É, pois, na preparação desse meio especial de educação - a escola - que podemos e devemos dispor as condições pelas quais a criança venha a crescer em saber, em força, em felicidade (TEIXEIRA, 1959, p. 20). 
A ideia de intencionalidade na preparação das condições para a aprendizagem permite refutar as críticas à "escola do interesse", em que supostamente as crianças seriam abandonadas ao seu próprio interesse quando o assunto fosse direção do processo de aprendizagem. Porém, também não é o contrário. Não se converte em coerção, porque leva em conta o papel ativo do indivíduo na própria aprendizagem. Anísio Teixeira ressalta que a direção, enquanto possibilidade de intervenção e condução do processo educativo, não se configura, de nenhum modo, na pedagogia deweyana, como coerção ou compulsão. "Estamos longe da velha suposição de que as tendências naturais do indivíduo são todas egoísticas ou antissociais, constituindo a educação no esforço para subordiná-las a um sentido exato de vida coletiva." (TEIXEIRA, 1959, p. 22) Dewey entende o indivíduo como ser social que só existe em sociedade. Nesta ele não suprime sua individualidade, mas a realiza.

“A tarefa de direção importa, assim, em selecionar, focalizar e ordenar a resposta à situação, dando orientação, coordenação e continuidade às múltiplas reações do nosso organismo" (TEIXEIRA, 1959, p. 23, grifo no original). É importante ressaltar que resposta aqui não é entendida como consequência prevista determinada por um estímulo específico, mas está ligada às reações que têm de nascer de tendências existentes no indivíduo. Isto é, a direção não pode ser exclusivamente externa. Ela tem de coadunar com a direção do próprio indivíduo sobre seus atos, "sob pena de ser incompleta ou prejudicial” (TEIXEIRA, 1959, p. 23).

Para Dewey, a aprendizagem que se integre diretamente à vida deve considerar pelo menos cinco princípios: 1) Só se aprende o que se pratica; 2) Praticar não é o bastante. A intenção de quem aprende tem singular importância; 3) Aprende-se por associação. Outras aprendizagens vêm associadas ao objetivo claro da atividade; 4) Não se aprende nunca uma coisa só. Uma aprendizagem não ocorre isolada, mas simultaneamente a outras; 5) Toda aprendizagem deve ter um significado real e ser vivida em uma experiência real de vida (DEWEY, 1959; TEIXEIRA, 1959).

A seu modo, na apreciação da pedagogia deweyana, Teixeira (1959) antecipa a crítica de Paulo Freire que viria a dar significado ao termo "educação bancária". Assim diz ele: "Tudo era ensinado na sua ordem lógica, independente da aplicação e das relações reais. Mais tarde o aluno sacaria contra esse capital acumulado, para utilizá-lo na vida real.” (p. 39, grifo nosso)

O aluno, não vendo nenhuma relação da "matéria" com sua vida presente ou qualquer empreendimento em que esteja empenhado, não pode ter motivo para se esforçar; não tendo motivo, não pode ter desejo ou intenção de aprender (salvo motivos artificiais ou falsos); não tendo a intenção de aprender, não pode assimilar ativamente a matéria, integrando-a à sua própria vida (TEIXEIRA, 1959, p. 40). 
O conceito de educação e de aprendizagem de Dewey não é estático, porque a vida não é estática. Não se completa em definitivo o processo de aprendizagem em determinado momento da vida ou da escolarização. Então, para ele, “o fim da educação não é a vida completa, mas a vida progressiva, vida em constante ampliação e em constante ascensão" (TEIXEIRA, 1959, p. 47).

Para Dewey, o processo educativo consiste na adequada interação entre a imaturidade da criança e certas ideias e valores representados pelo adulto amadurecido. "A concepção das relações entre um e outro, tendente a tornar fácil, livre e completa essa interação, é a essência da teoria educativa" (DEWEY, 1959, p. 50, grifo nosso). Dewey reconhece que a aprendizagem não se efetiva como a satisfação de uma necessidade de uma vez por todas.

O homem não aprende por uma necessidade que, satisfeita, faça desaparecer aquela capacidade. Aprender é, muito pelo contrário, uma função permanente do seu organismo, é a atividade pela qual o homem cresce, mesmo quando seu desenvolvimento biológico de há muito se completou. Essa capacidade de aprender permite uma educação indefinida, um indefinido crescimento. (TEIXEIRA, 1959, p. 27, grifo no original).

"Aprender, aliás, além de ser o modo de adquirir hábitos, pode tornar-se um hábito em si mesmo" (TEIXEIRA, 1959, p. 29). Dessa forma, os fins da educação se sucedem progressivamente. À medida que são concretizados, transformam-se em meios para alcançar novos fins, em perspectivas cada vez mais amplas. Em educação, a criança é a medida e o julgamento, porque ela é “o ponto de partida, o centro e o fim” (DEWEY, 1959, p. 55). Na crítica que faz à escola tradicional, à qual chama de velha escola, Dewey faz um paralelo entre o que defende essa escola e a renovação proposta, especialmente no que se refere ao par disciplina e controle: “'direção e controle’ são as palavras mágicas de uma escola; 'liberdade e iniciativa', as da outra" (DEWEY, 1959, p. 57, aspas no original), mas mostra-se consciente das mútuas críticas realizadas pela nova e pela velha escola:

Inércia e rotina por um lado, caos e anarquia do outro, são as mútuas acusações condenatórias. A escola que faz da criança o centro de tudo é acusada de desprezar a autoridade sagrada do dever; ela, por sua vez, ataca na sua opositora a supressão da individualidade através de um despotismo tirânico (DEWEY, 1959, p. 57).

Ainda conforme Dewey (1959), essas posições raramente são levadas às últimas consequências lógicas. Elas conduziriam também, de acordo com o autor, a uma disputa teórica enquanto na prática predominaria um ecletismo indefinido. Ele escreve um item intitulado "Os exageros da velha e da nova educação", em que coloca nos devidos termos as interpretações e 
práticas dessas perspectivas educacionais e as práticas que delas decorrem. Por um lado, critica a velha educação pela comparação que faz entre a imaturidade da criança e a maturidade do adulto e a consequente crença na necessidade de libertação da imaturidade. Por outro, alerta sobre o perigo de se considerar o interesse da criança como portador de uma significação definitiva. Para ele, o interesse da criança são as atitudes delas em relação às experiências possíveis. $\mathrm{O}$ valor da capacidade da criança reside "antes na propulsão para um nível mais alto que delas pode resultar" (DEWEY, 1959, p. 63).

\section{Organização das aprendizagens - o interesse e a lógica psicológica}

Para Dewey, a organização lógica das aprendizagens em detrimento da psicológica possui uma dupla contradição. A criança não aproveita a sistematização lógica do adulto nem as possibilidades de apreensão segundo suas capacidades. Mas Dewey se lembra de refutar o falso arranjo psicológico das matérias. Isto é, o interesse deve se ligar àquilo que se aprende. Não há necessidade de truques e de motivações externas para "tornar o assunto interessante" (DEWEY, 11959, p. 76). Pelo legítimo princípio de interesse, o indivíduo "reconhece uma identificação entre o fato que deve ser conhecido ou a ação que deve ser praticada e o agente que por essa atividade se vai desenvolver" (DEWEY, 1959, p. 88, grifo no original). A própria etimologia da palavra "interesse" - estar entre - explicaria que o interesse suprime a distância entre quem aprende e o conteúdo da aprendizagem e os resultados de sua ação.

Ainda quanto aos arranjos feitos às matérias, visando torná-las "interessantes", Dewey condena totalmente a ideia de que primeiro se escolhe a matéria, para depois torá-la interessante aos olhos do aluno. Para o autor, o interesse é normal, educativamente legítimo e digno de confiança, na medida em que a atividade que ele envolva possa se desenvolver progressivamente.

Para Dewey, quando ocorre interesse verdadeiro, "significa, pois, que uma pessoa se identificou consigo mesma, ou que se encontrou a si mesma, no curso de uma ação. E daí se identificou com o objeto ou forma de habilidade necessária à prossecução feliz de sua atividade" (DEWEY, 1959, p. 120). O autor não nega o papel do esforço, mas esclarece também o que é o esforço válido para a Escola Nova. O esforço só tem sentido em vista do fim a ser atingido. No entanto, trata-se de esforço enquanto "persistência, continuidade de ação: tenacidade apesar dos obstáculos e das dificuldades. Esforço, entendido como simples dispêndio de força e de energia, não é, porém o que deve preocupar o educador” (DEWEY, 1959, p. 122, grifo no 
original). Tendo em vista a perspectiva mediadora da educação, Dewey conceitua o "motivo". Motivo, para ele, é o nome que se dá ao "fim", quando considerado sob a perspectiva da capacidade que ele tem de influenciar a ação no presente. Na velha escola,

acreditava-se que pura força de vontade, esforço arbitrário, era somente o de que se precisava. Na prática, isso sempre quis dizer, como vimos, apelo a fontes extrínsecas de motivação: respeito pela autoridade do livro ou do mestre; medo de castigo ou de descontentar os outros; sucesso na vida adulta; conquista de prêmios; aparecer melhor que os outros; receio de não ser aprovado, etc. (DEWEY, 1959, p. 134-135).

Outra consequência danosa "de um conceito muito personalista de motivação é a concepção estreita e externa do uso das matérias de ensino. É justificável indagar da utilidade de qualquer matéria de ensino" (DEWEY, 1959, p. 136-137). Como essa utilidade poderia vir a ser questionada sob diferentes pontos de vista, Dewey esclarece que ela vem do caráter mediador da educação que postula. Ainda tendo em vista o caráter mediador do ensino, é importante atentar para seu conceito de atividade.

Não há nada de novo ou sensacional nessa concepção de atividade como um
importante princípio educativo. No sentido de 'self-activity', em particular,
atividade tem sido desde muito tempo o nome para um fim último da
educação. Foi, entretanto, interpretada num sentido de atividade interna
tornando-se um ideal estéril e sem influência na prática, não sendo algumas
vezes mais do que uma simples frase, que recebia somente homenagens dos
lábios dos educadores. (DEWEY, 1959, p. 138, grifo no original)

A concepção de jogo e de trabalho exposta por Dewey coloca a intencionalidade e a condição de sujeito como necessidade do processo de aprendizagem. "Entendido, porém, o trabalho como atividade que requer meios intermediários para ser efetivada, jogo e trabalho não podem ser diferenciados ou distinguidos um do outro pela presença ou ausência de interesse no que se está fazendo" (DEWEY, 1959, p. 150, grifo no original). Dewey completa:

Definindo trabalho como o definimos, essa expressão abrange todas as atividades que envolvem o uso de material intermediário, de aparelhos e de formas de habilidade, conscientemente aplicados na realização de certos resultados. Todas as formas de expressão e de construção com instrumentos e materiais, todas as formas de atividade manual e artística, constituem trabalhos, sempre que requeiram esforço consciente ou refletido para se realizarem. (DEWEY, 1959, p. 152)

Se não cabe distinguir o trabalho do jogo, há que se reconhecer que a ação da criança no processo de aprendizagem também é trabalho. Ela trabalha para objetivar o que estabeleceu prévia e internamente - trabalha movida pelo interesse que acompanha um objetivo seu, deliberadamente estabelecido. 


\section{O caráter mediador da administração escolar - discussões atuais}

Não se pretende aqui comparar Dewey com as discussões atuais do campo educacional, pois se tem presente o contexto de vida do autor e da produção de sua obra. No entanto, sua obra deixou um legado para a educação. É no sentido de cotejar as contribuições que podem ainda ser observadas pelo campo educacional na discussão específica da Administração Escolar que se busca compreender, nesta seção o conceito de Administração Escolar.

Ao se propor compreender o conceito geral de administração, isto é, compreender a administração abstraída de suas determinações histórico-sociais, Paro (2012, p. 25) afirma que “a administração é a utilização racional de recursos para a realização de fins determinados". Então, postula que, assim entendida, a administração também é uma atividade exclusivamente humana, pois somente a espécie humana é capaz de estabelecer livremente objetivos para suas ações. Daí a importância da administração. Enquanto mediadora, ela possibilita atingir da melhor forma possível os fins estabelecidos (PARO, 2010b, 2012). Portanto, só o homem é capaz de racionalizar recursos (objetivos e subjetivos) para a sua consecução. Ainda segundo o autor, os recursos objetivos designam "as condições objetivas presentes na realização do trabalho ou dos trabalhos que concorrem para a realização dos fins da empresa ou organização" (PARO, 2010b, p. 767). Os recursos subjetivos se referem ao que Marx chamou de força de trabalho ${ }^{3}$.

Ao tratar das necessárias relações entre os homens na produção de sua existência, Paro (2012) afirma que essas relações envolvem esforço humano e que, embora nada impeça a aplicação a uma ação isolada, os princípios da utilização racional dos recursos se ocupam especialmente do esforço humano coletivo. A essa utilização racional do esforço humano coletivo, o autor denomina "coordenação do esforço humano coletivo" (PARO, 2012, p. 31). Dessa forma, a "racionalização" se refere à relação homem-natureza e a "coordenação", às relações dos homens entre si. São esses dois os campos que se interpenetram e caracterizam a administração. Ainda de acordo com o autor,

os elementos materiais e conceptuais não cumprem sua função no processo se não estiverem associados ao esforço humano coletivo; da mesma forma, o esforço humano coletivo necessita dos elementos materiais e conceptuais para ser aplicado racionalmente (PARO, 2012, p. 32).

${ }^{3}$ Note-se que essa abordagem se difere da abordagem: recursos humanos/recursos materiais. Nesta, os elementos conceptuais seriam recursos humanos e o esforço humano não teria lugar. Paro (2012), ao contrário, não considera o homem como "meio", mas como "fim". Isto é, não como objeto no processo de busca de realização de fins. Considerá-lo meio implica dominação. A dominação desconsidera o que caracteriza o homem. Ele é homem porque domina a natureza. Enquanto homem, um precisa reconhecer no outro essa capacidade. Eis porque defender a cooperação em vez da dominação (PARO, 2012). 
Ainda acerca do caráter mediador da Administração Escolar, Paro (2010) destaca a convergência das opiniões acerca da importância da organização e gestão escolar nos textos acadêmicos, no discurso governamental, midiático e no senso comum. Nestes três últimos, o entendimento é que se a educação vai mal, boa parte da culpa é da administração que a tem como foco. Fato é que de forma crítica ou não, atribui-se uma importância à administração da educação, o que possibilita reafirmá-la como “mediação para a realização de fins" (p. 765).

O conceito inicial adotado pelo autor é geral. Engloba todo tipo de administração, independente da natureza do que se administra, do setor, momento ou processo a que se refira. "Isso nos permite falar em administração de pessoal, administração de material, administração financeira, assim como administração de atividades-meio, administração de atividades-fim ${ }^{4}$, etc.” (p. 765). A mediação, nesse caso, não se restringe às atividades-meio, mas se prolonga pelas atividades-fim, na busca da concretização dos objetivos. De acordo com o autor, a noção de administração apenas ligada às atividades-meio, isto é, que não leva em conta o caráter administrativo do processo pedagógico leva a valorizar apenas o papel do diretor escolar. Posicionando-se contra essa perspectiva, o autor constata que o conceito de administração que comumente ancora os estudos sobre a gestão escolar separa as atividades-meio e as atividadesfim como mutuamente exclusivas, "encobrindo assim o caráter necessariamente administrativo de toda prática pedagógica e desconsiderando as potencialidades pedagógicas da prática administrativa quando se refere especificamente à educação" (PARO, 2010b, p. 766).

Compreendendo a escola como empreendimento humano organizado para alcançar determinados fins por meio do esforço coletivo, convém, por fim, ressaltar o posicionamento radical de Anísio Teixeira quanto ao caráter mediador da Administração Escolar.

A intenção [...] foi antes a de sublinhar o caráter e natureza da administração escolar como função que somente pode ser exercida por educadores e que é intrinsecamente de subordinação e não de comando da obra de educação que, efetivamente, se realiza entre o professor e o aluno, os dois fatores realmente determinantes da sua eficiência (TEIXEIRA, 1968, p 16-17).

Nessa citação, Anísio Teixeira deixa clara a necessidade de a administração levar às últimas consequências seu caráter de mediação. A subordinação a que ele se refere diz respeito à função da administração de prover as condições para que o trabalho do professor e do aluno

${ }^{4} \mathrm{O}$ mesmo autor, em outro livro (PARO, 2001), define como atividades-meio aquelas viabilizadoras do processo pedagógico, como direção e atividades administrativas, e como atividades-fim as que se referem ao ensino e à aprendizagem, isto é, aquelas que lidam diretamente com questões pedagógicas, como supervisão, orientação e a docência. Importante que essa definição é apenas didática, uma vez que o autor se posiciona contrário à dicotomia entre essas atividades. 
possa ser realizado. Dessa forma, Teixeira propõe a inversão do modo como se costuma efetivar a administração escolar até os dias atuais - de subordinadora a subordinada.

É importante verificar como os princípios da pedagogia advogada por Dewey permitem refletir sobre as políticas e práticas da administração escolar atual. Em um contexto crescente das demandas de elevação de escores de rendimento na testagem de alunos em larga escala, em que os princípios como accountability (prestação de contas) e quase-mercado tendem a (re)introduzir ou reforçar na administração escolar os princípios do Estado Gerencial, o legado de "Vida e educação" permitem voltar o olhar para o cerne do fenômeno educativo, ao qual a administração escolar subordina-se.

Cabe evocar a pergunta de Paro (2009, p. 456): “Como pode, pois, aplicar-se à escola (uma instituição sabidamente do âmbito do diálogo e da afirmação de subjetividades, não da dominação) os mesmos princípios e métodos administrativos da empresa capitalista, sem que os meios contradigam os fins? Sem que, portanto, se negue o caráter mediador da administração anteriormente afirmado?" Diante de tal pergunta, resta lembrar que, no atual contexto, a preocupação com a prestação de contas e os processos gerenciais, de necessários instrumentos que deverias auxiliar no alcance dos fins da educação, convertem-se nos próprios fins da educação.

\section{Considerações finais}

Obviamente Dewey deve ser situado em seu tempo. No entanto, sua obra deixa um legado para a Educação, mediante conceitos e princípios que podem orientar uma discussão de administração escolar na atualidade.

Essas contribuições de "Vida e educação" para a administração escolar estão em pelo menos quatro premissas. A primeira é a afirmação de Dewey de que a intervenção (ou direção) do processo educativo tem seu cerne na preparação das condições favoráveis para que o indivíduo se interesse e se envolva no processo de aprendizagem, porque se compreende que a ação do sujeito que aprende é decisiva para a efetivação da aprendizagem, e não o método de ensino. A segunda é que "a administração é a utilização racional de recursos para a realização de fins determinados" (PARO, 2012, p. 25). Ou seja, a administração escolar se subordina aos fins da atividade que ela tem por objeto. A terceira é a concepção de educação e de escola de Dewey, que é fundamentalmente de caráter mediador para aprendizagens cada vez mais amplas. Por fim, a importância da experiência democrática na pedagogia deweyana em relação à 
centralidade da atividade do indivíduo que aprende - não como mera atividade, mas no exercício do papel de sujeito.

Administrar é, portanto, prover e fazer uso racional das condições necessárias para o desenvolvimento do interesse e, em última instância, para o desenvolvimento de personalidades para uma sociedade democrática. $\mathrm{O}$ caráter administrativo dessa escola também não permite compreender de forma dicotômica as atividades-meio como exclusivamente administrativas nem as atividades-fim como exclusivamente pedagógicas, pois será função de todas as instâncias da escola prover e fazer uso de recursos e condições para levar o aluno a se interessar e aprender.

Se a direção do processo educativo - isto é, a intervenção - está calcada na necessidade de criar o interesse, a providência das condições necessárias à criação desse interesse se constituirá em atividade administrativa, envolvam essas ações a gestão dos recursos materiais necessários ou a coordenação do esforço humano coletivo. Nesse esforço humano coletivo inclui-se o aluno, que age, trabalha, para aprender. Falar da direção do processo de aprendizagem pelo professor não é outra coisa senão reconhecer o caráter administrativo que perpassa também as atividades pedagógicas.

Tendo em vista o caráter mediador da Administração Escolar que se tomou como referência neste texto e a compreensão da filosofia educacional em "Vida e educação", podese depreender que a administração escolar que leva em conta as contribuições de tal obra deve ter como foco o aluno, considerando a condição de sujeitos dos indivíduos-alvo de sua ação. Constitui-se em administração que se faz de forma democrática, não como mera imitação, mas como processo real, por meio do qual a discussão das práticas sociais e das instituições exige a distribuição equitativa de interesses. Se a direção do processo educativo não é coercitiva, mas deve combinar direção externa com interna, a administração escolar não pode se realizar de forma vertical, sob pena de contradizer a filosofia educacional, por meio da qual se estabelecem os fins da educação e da escola.

\section{REFERÊNCIAS}

DEWEY, John. Vida e educação. 5. ed. São Paulo: Companhia Editora Nacional, 1959.

LOURENÇO FILHO, Manuel B. Prefácio. In: DEWEY, John. Vida e educação. 5. ed. São Paulo: Companhia Editora Nacional, 1959. 
OZMAN, H. A.; CRAVER, S. M. Fundamentos filosóficos da educação. Porto Alegre: Artmed, 2004.

PARO, Vitor Henrique. Gestão democrática da escola pública. São Paulo: Ática, 2001.

PARO, Vitor Henrique. Educação como exercício do poder: crítica ao senso comum em educação. 2. ed. São Paulo: Cortez, 2010a.

PARO, Vitor Henrique. A educação, a política e a administração: reflexões sobre a prática do diretor de escola. Educação e Pesquisa. São Paulo, v. 36, n.3, p. 763-778, set./dez. 2010 b.

PARO, Vitor Henrique. Administração escolar: introdução crítica. 17. ed. rev. ampl. São Paulo: Cortez, 2012.

TEIXEIRA, Anísio Spínola. A pedagogia de Dewey. In: DEWEY, John. Vida e educação. 5. ed. São Paulo: Companhia Editora Nacional, p. 1-49, 1959.

TEIXEIRA, Anísio Spínola. Natureza e função da administração escolar. In: TEIXEIRA, Anísio Spínola et al. Administração escolar. Salvador: Anpae, p. 9-17, 1968.

WESTBROOK, Robert B (Org.). John Dewey. Recife: Fundação Joaquim Nabuco, Editora Massangana, 2010. (Coleção Educadores).

\section{Como referenciar este artigo}

ARAÚJO, Abelardo Bento. Um legado de John Dewey para a administração escolar: uma leitura da obra Vida e educação. Revista on line de Política e Gestão Educacional, Araraquara, v. 23, n. 2, p. 356-369, maio/ago., 2019. E-ISSN:1519-9029. DOI: 10.22633/rpge.v23i2.12378

Submetido em: 22/03/2019

Revisões requeridas: 10/04/2019

Aprovado em: 21/04/2019

Publicado em: 15/05/2019 